\title{
Building the Terracotta Army: ceramic craft technology and organisation of production at Qin Shihuang's mausoleum complex
}

Patrick Sean Quinn ${ }^{1, *}$, Shangxin Zhang ${ }^{2,3}$, Yin $\mathrm{Xia}^{2} \&$ Xiuzhen $\mathrm{Li}^{2}$

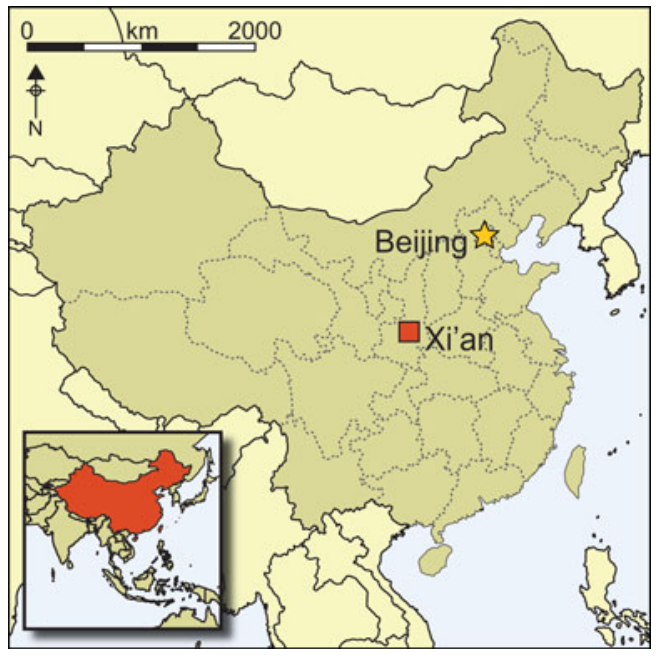

Despite decades of research into the Terracotta Army of the First Emperor of China, many questions remain about how, where and by whom the figures were made. This new study compares the results of microscopic analysis of the life-sized clay statues to other ceramic artefacts recovered from the mausoleum. By focusing on their original raw materials and clay paste recipes, it proves that the terracotta warriors were made near the site. Compositional, technological and spatial links between different artefacts suggest that clay was processed centrally before being distributed to different local workshops in a highly organised system of labour and craft specialisation that laid the foundation for imperial China.

Keywords: China, Qin Shihuang, Terracotta Army, clay, petrography

\section{Introduction}

The enormous mausoleum complex of Qin Shihuang, the First Emperor of China, is a funerary site of unparalleled importance that is thought to represent a microcosm of his imperial kingdom (Yuan 1990) (Figure 1a). Construction of the elaborate necropolis in Lintong, near Xi'an, Shaanxi Province, China, began when 13-year-old Qin Shihuang ascended to the throne in $247 \mathrm{BC}$, and was completed upon his death less than 40 years later (Yuan 1990). The workforce may have involved up to 700000 craftsmen and labourers

\footnotetext{
Institute of Archaeology, University College London, 31-34 Gordon Square, London WC1H OPY, UK Emperor Qin Shihuang's Mausoleum Site Museum, Lintong, Xi'an 710600, China

3 School of Humanities, University of Chinese Academy of Sciences, 19 Yuquan Road, Shijingshan District, Beijing 100049, China

* Author for correspondence (Email: patrick.quinn@ucl.ac.uk)
} 


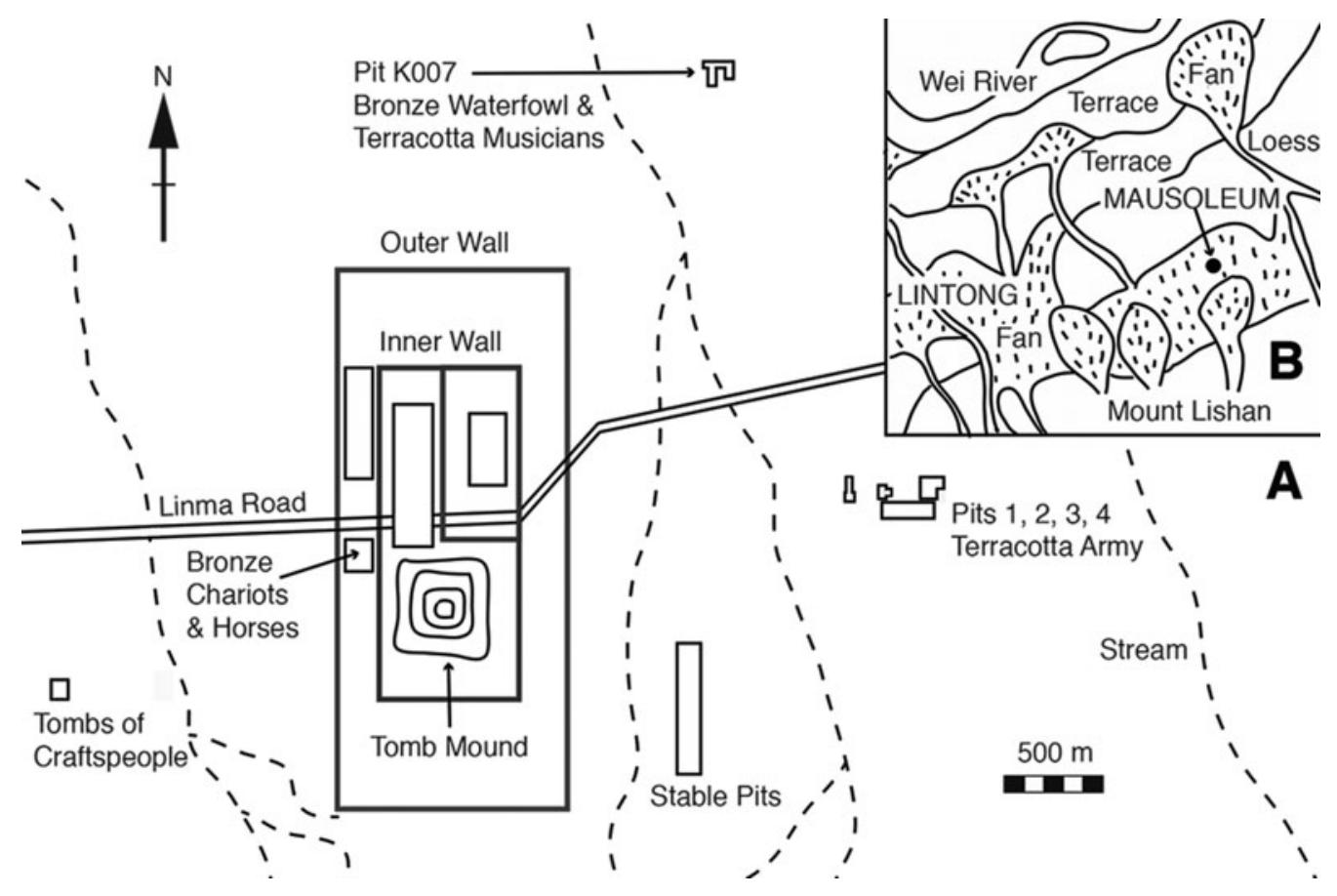

Figure 1. Emperor Qin Shihuang's mausoleum site in Shaanxi Province, China. a) Plan of the mausoleum site with the location of pits mentioned in text; b) map of Quaternary sedimentary deposits in the vicinity of Lintong (modified from Lei et al. 2004: 38, fig. 1).

from all corners of the Qin Empire, some of whom were slaves who may have been executed once they had fulfilled their duties (Yang \& Yang 1979; Ledderose 2001: 273). Given that nothing of its kind appears to have existed previously in China, this project would have represented a monumental undertaking that presented numerous technological and logistical challenges.

The most renowned aspect of the site is the Terracotta Army, which comprises around 7000 individually crafted, life-sized ceramic warriors, generals and horses, equipped with real weapons and installed in battle formation in three underground pits (Figures 1a \& 2a). Several decades of research into the Terracotta Army has resulted in a good understanding of the physical sequence of constructing the statues (Ledderose 2000; Nickel 2007). Many questions still remain, however, about their production location(s), manufacturers and craft technology. For example, it is usually assumed that due to the size and weight of the figures, they were probably produced at or near to the mausoleum. No workshops or unequivocal production debris have, however, been discovered in the surrounding landscape; possible mismatches with local raw materials may suggest that they were manufactured elsewhere (e.g. Gao et al. 2003; Hu et al. 2007). Firing so many life-sized clay statues, which have a wall thickness of up to $0.1 \mathrm{~m}$, without large numbers of failures, would have required excellent control over temperature and atmosphere, and the careful selection and preparation of raw materials. While kilns large enough to accommodate the $1.8-2 \mathrm{~m}$-high soldiers and horses have been found, these contained fragments of bricks and roof tiles 


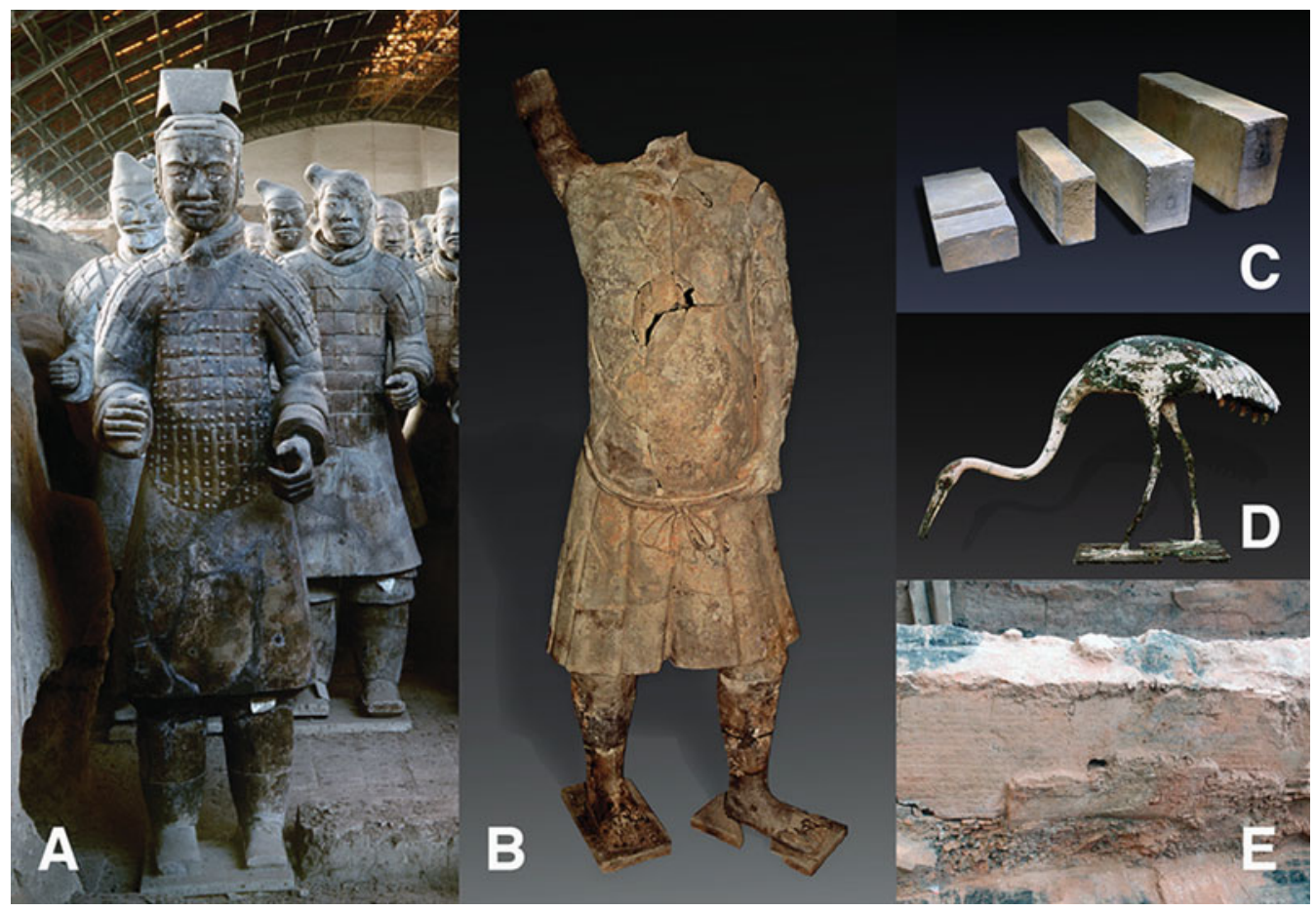

Figure 2. Ceramic artefacts analysed in this study: a) terracotta warrior statue; b) terracotta acrobat; c) bricks used to line pit 1; d) bronze waterfowl; e) rammed-earth wall. (Images $b-d$ provided by Tianzhu Zhang.)

(Li 2007a), prompting some researchers to propose that the warriors were bonfire-fired, or simply left to dry (Wiedemann et al. 1988; Shan et al. 2003). Interpretations of the paste-preparation technology used in the manufacture of the Terracotta Army are equally contradictory, with suggestions of both the intentional modification of raw materials as well as the use of unrefined local clay (Wiedemann et al. 1988; Qin et al. 1989; Shan et al. 2003).

Determining the details of how the terracotta statues were manufactured is crucial for addressing wider questions concerning the craft logistics, standardisation and labour organisation behind the mausoleum complex of the First Emperor, and the administrative procedures of Qin-period China more generally (Barbieri-Low 2007; Yates 2007; Li et al. 2016). Key questions include the number, size and location of the different workshops involved in the manufacture of the approximately 7000 figures, their cultural/political affiliations, internal organisation and specific roles in the project. Also of interest are possible links between the production of the terracotta statues and other crafts at the mausoleum, and what this can tell us about the planning and administration of the project as a whole.

\section{Study materials and analytical methods}

As a first step, we studied an initial dataset of terracotta statue fragments and compared these to ceramic building materials and to clay cores used for the casting of bronze artefacts (C) Antiquity Publications Ltd, 2017 
Table 1. Details of ceramic samples analysed from Emperor Qin Shihuang's mausoleum site. QMC = Qin mausoleum ceramics.

\begin{tabular}{llll}
\hline Sample & Object & Details & Findspot \\
\hline & & & \\
QMC001 & terracotta warrior statue & robe? & pit 1 \\
QMC002 & terracotta warrior statue & hand & pit 1 \\
QMC003A & terracotta warrior statue & armour lace & pit 1 \\
QMC003B & terracotta warrior statue & armour scale & pit 1 \\
QMC004 & terracotta warrior statue & robe with purple paint and soil deposit & pit 1 \\
QMC015 & brick & striated surface & pit 1 \\
QMC005 & terracotta warrior statue & leg with lacquered external surface & pit 1 \\
QMC006 & terracotta warrior statue & not known & pit 1 \\
QMC007 & terracotta warrior statue & not known & pit 1 \\
QMC016 & brick & striated surface & pit 1 \\
QMC017 & brick & striated surface & pit 1 \\
QMC018 & brick & striated surface & pit 1 \\
QMC008 & terracotta warrior statue & not known & pit 1 \\
QMC009 & terracotta warrior statue & robe? with lacquered external surface & pit 1 \\
QMC010 & terracotta warrior statue & not known & pit 1 \\
QMC011 & terracotta warrior statue & not known & pit 1 \\
QMC012 & terracotta warrior statue & not known & pit 1 \\
QMC019 & brick & striated surface & pit 1 \\
QMC013 & terracotta acrobat statue & not known & pit K9901 \\
QMC014 & terracotta acrobat statue & not known & pit K9901 \\
QMC020 & bronze waterfowl core & neck of unknown bird type & pit K007 \\
QMC021 & bronze waterfowl core & body of swan 13 & pit K007 \\
QMC022 & bronze waterfowl core & neck of crane 28 & pit K007 \\
QMC023 & rammed earth & - & pit K9901 \\
\hline
\end{tabular}

excavated from the site (Table 1; Figure 2). All samples were analysed microscopically via thin-section petrography (Quinn 2013) to characterise their raw materials, methods of paste preparation and firing. The resulting data has been used to address several unanswered questions concerning the ceramic craft technology and production locations of the terracotta statues and other ceramic objects.

Our sample set includes 12 fragments of terracotta warrior statues originating from the largest of the three pits, pit 1 (Figure 1a), which contained the main army. These samples represent different parts of their parent artefacts, including the leg, hand, robe and armour (Figure 2a). Two fragments of 'terracotta acrobat' statues (Figure 2b) recovered from pit K9901 (Figure 1a) were also made available for study. Five clay paving bricks from the floor of pit 1 (Figure 2c) were analysed for comparison with the statues, as were three samples of clay core material located within the body or neck sections of several ornate bronze statues of waterfowl (Figure 2d) found in pit K0007 (Figure 1a). Finally, a single sample of rammed-earth wall (Figure 2e) from pit K9901 (Figure 1a) was also studied.

All ceramic artefacts were prepared as $30 \mu \mathrm{m}$ thin sections and were analysed with a transmitted polarising light microscope at magnifications of $\times 25-400$. The samples were grouped into petrographic fabrics based on the nature of their particulate inclusions, 

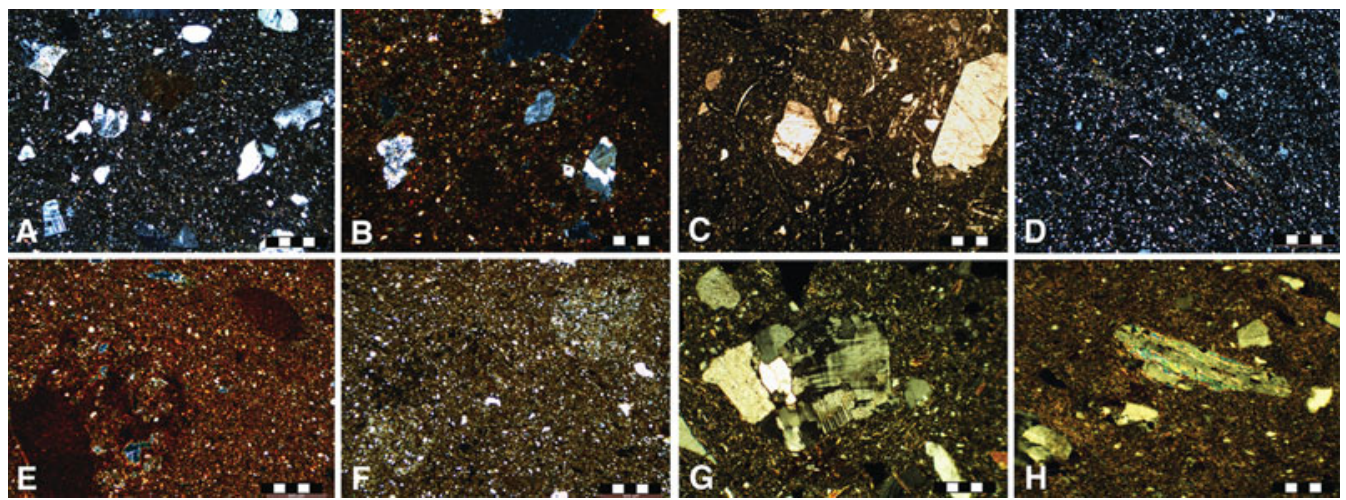

Figure 3. Thin-section photomicrographs of petrographic fabric groups and specific features detected within ceramic artefacts in this study. a) Sand-tempered terracotta warrior statue; b) sand-tempered terracotta acrobat fragment; c) sand-and-planttempered core sample from bronze waterfowl; d) untempered silty brick sample; e) dark, clay-rich plastic inclusion that may indicate intentional clay mixing; f) light-coloured plastic inclusion in sample that may indicate the intentional mixing with the material in the previous image; g) granite rock fragment within sand temper; h) phyllite metamorphic rock fragment within sand temper. Image width $=0.5 \mathrm{~mm}$, except $g$ and $h=0.25 \mathrm{~mm}$. Images taken under crossed polars, except $c$ and $f$, taken in plane polarised light.

clay matrix and voids. Quantitative modal and textural data were also collected via point counting a total of 300 evenly spaced points (Quinn 2013: 102-11), using a PETROG digital stepping stage and software.

\section{Petrographic composition, raw materials and manufacturing technology}

All samples appear to have been produced with a non-calcareous clay paste, rich in angular, silt-sized inclusions of quartz and biotite mica (Figure 3). Inconspicuous clay-rich inclusions occur within the samples (Figure 3e-f). These could represent poorly hydrated remnants of a fine, dark clay source and a lighter, more silty variety, which were mixed together to produce a single paste with specific functional or aesthetic properties (Quinn 2013: 16871). Naturally occurring 'argillaceous' inclusions can, however, also occur in clay deposits and may be transferred to ceramics made from such clay (Whitbread 1986).

The clay used to manufacture the ceramics may have been procured from the extensive loess deposits that exist in the Lintong region (Figure $1 \mathrm{~b}$ ) and that cover much of northwestern China. These represent an almost limitless supply of raw material that has been used for the production of various ceramic types (Freestone et al. 1989; Wood 2000; Stoltman et al. 2009). Previous compositional analyses of the Terracotta Army also concluded that they were made from local loess, which has a fine, micaceous, clay-rich character (Gao et al. 2003; Shan et al. 2003; Rong \& Lan 2005). The geochemical links that have been proposed by Gao et al. (2003: 68, fig. 3) and Shan et al. (2003: 303, fig. 4) are, however, less than convincing.

This common base clay appears to have been treated in several ways, resulting in three distinct petrographic fabrics that correlate with artefact type. The paste of the terracotta warrior and acrobat statues was prepared by the addition of sand temper (Figure 3a-b);

(C) Antiquity Publications Ltd, 2017 
the core material of the bronze waterfowl was produced by adding sand and chopped plant matter (Figure 3c); and the bricks lining the floor of pit 1 and rammed-earth sample from pit K9901 seem to have been fashioned from the untempered clay described above (Figure 3d).

The identification of sand temper was based on the grain-size distribution of the coarser statue and core samples, which is strongly to weakly bimodal (Figure 4), by its often uneven penetration into the base clay, and by comparison with the untempered paste used for the bricks and rammed earth, which have a finer, better sorted, unimodal texture made up of intrinsic silt-sized inclusions (Figure 3d). Naturally occurring clay and sediment samples do not usually contain bimodal grains, due to the grading of material via water or wind.

Sand temper could have been added to control the plasticity or 'stickiness' of the fine clay and make it more suitable for shaping into the ornate warrior and acrobat statues. It would also have 'opened up' the paste, creating pores through which water could evaporate. The absence of parallel-sided elongate voids in the statue samples indicates that these thick-walled objects were dried carefully before firing. Sand temper may also have been added to give the statues greater toughness once fired, reducing the possibility of failure when impacted. The ceramic core material inside the bronze waterfowl was probably sand tempered for similar reasons.

The composition of the sand-sized temper inclusions provides important clues about their geological origin. In addition to the dominant quartz and polycrystalline quartz grains, this material contains a smaller ( $<50$ per cent) proportion of other inclusions, such as alkali and plagioclase feldspar, perthite, amphibole, biotite mica, epidote, phyllite, slate, sandstone, siltstone, micritic limestone and granite (Figure $3 \mathrm{~g}-\mathrm{h}$ ). This high diversity of clasts suggests that the source of the temper was a 'polymict' sand deposit. The absence in thin section of agglomerates indicates that the sand was collected in a loose form, rather than being produced by crushing sandstone. A possible source might, therefore, be Quaternary alluvial sand.

Fine plant matter was also added to the paste of the waterfowl cores. This carbonised and partially burned out, leaving distinctive voids that contain charred organic material (Figure 3c). It may have been added to reduce the overall weight of the core, as it would not have been possible to remove this material from the long necks of the sculptures after casting (Shao et al. 2015). The high porosity of the internal core (7.5-13 per cent; Figure 5) could also have facilitated venting of chemically combined water from the clay as the $>1000^{\circ} \mathrm{C}$ molten bronze was poured into the mould (Liu et al. 2013). This may have otherwise interfered with the casting of the delicate metal object.

Our petrographic analysis of 12 terracotta warrior statues has illuminated the muchdebated firing technology of these artefacts. Their rigidity and long-term preservation strongly suggests that the statues were intentionally fired, rather than simply being left to dry as suggested by Wiedemann et al. (1988). The survival of pollen within two previously analysed samples (Hu et al. 2007) might be explained by poor oxygen penetration into the walls of the thick ceramic samples - this is known to be critical for pollen degradation during the firing of ceramics. The presence of birefringence, or 'optical activity', in the clay matrix of the majority of the samples under the microscope in crossed polars suggests that 
Patrick Sean Quinn et al.
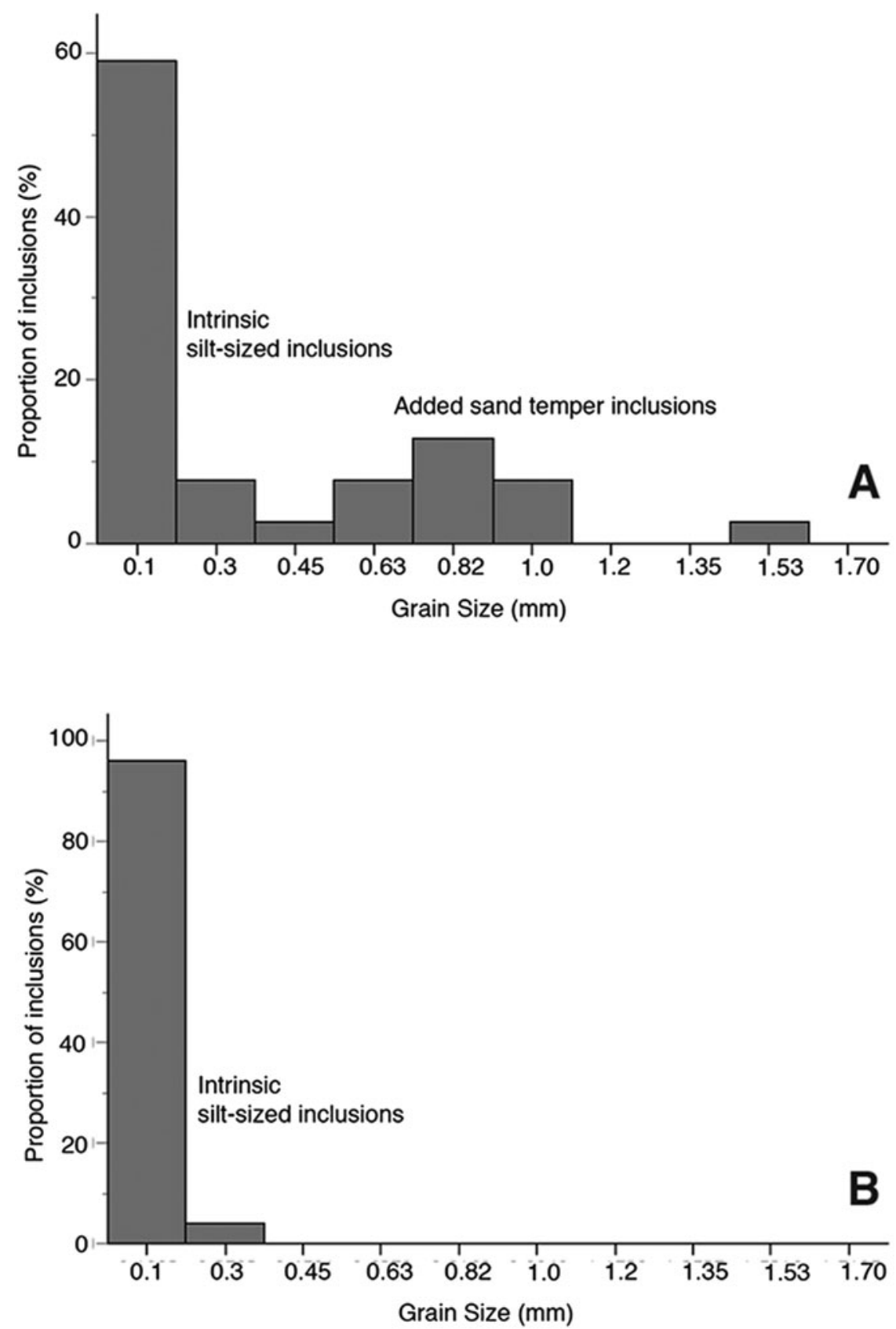

Figure 4. Grain-size distribution histograms of ceramic artefacts from Emperor Qin Shihuang's mausoleum site, based on detailed textural data collected on the inclusions in thin section. a) Bimodal grain-size distribution of inclusions in terracotta warrior statue sample; b) unimodal grain-size distribution of inclusions in brick sample.

(C) Antiquity Publications Ltd, 2017 


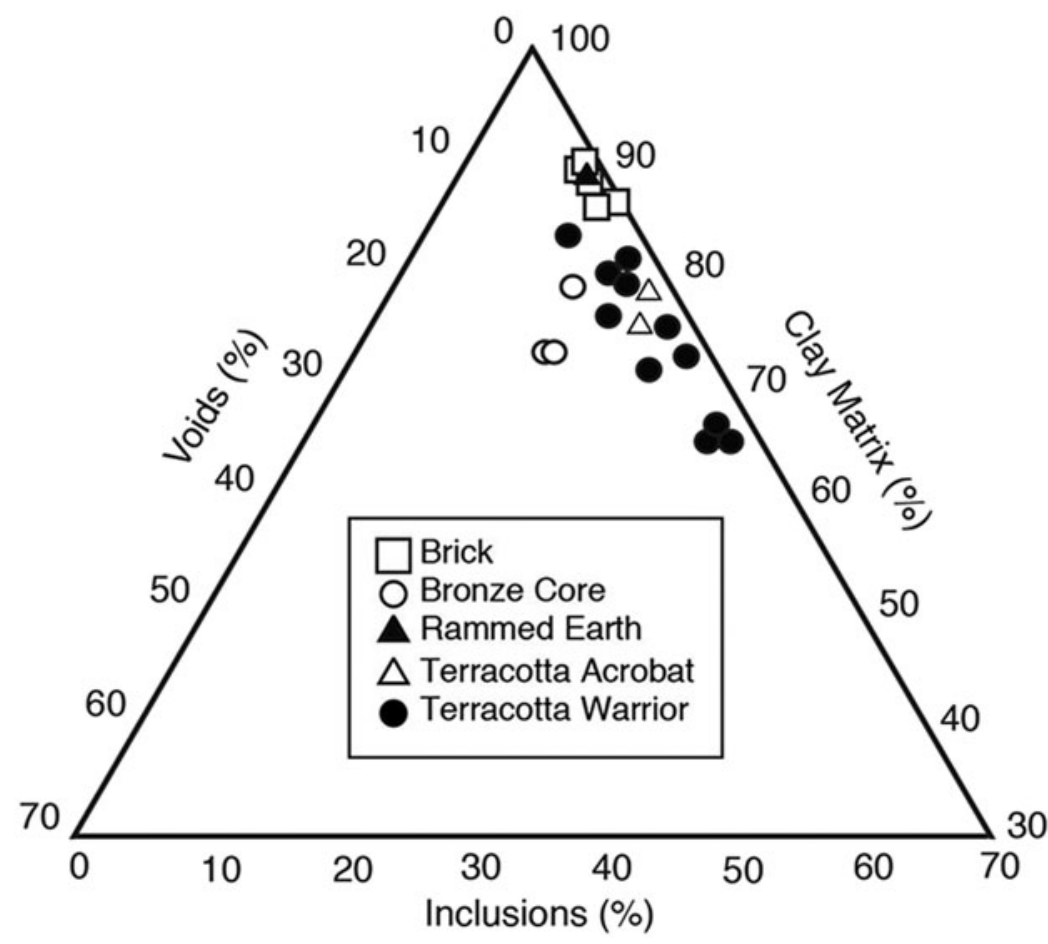

Figure 5. Ternary diagram of the proportion of inclusions, clay matrix and voids within ceramic artefacts from Emperor Qin Shihuang's mausoleum site, based on modal data collected in thin section.

the statues were not subjected to a sustained temperature $>850^{\circ} \mathrm{C}$ (Quinn 2013: 190-93). Common clay minerals, such as illite, begin to melt and lose their crystalline structure at this temperature. Inclusions of the mineral amphibole, which occur in many of the statue and bronze core samples, have a green colour under the microscope in plane polarised light, indicating a maximum firing temperature of $<750^{\circ} \mathrm{C}$.

Suggestions of firing temperatures of $900-1050^{\circ} \mathrm{C}$ (e.g. Yuan 1990) are not supported by our data, and would not have been necessary in order to harden the ceramics. It is worth bearing in mind, however, that the burning of the wooden roofs of the subterranean pits containing the Terracotta Army during their supposed destruction by General Xiang Yu in the late Qin period (Ledderose 2000) could have resulted in the accidental re-firing of certain statues, thus explaining the wide variation in firing-temperature estimates of different studies (Shan et al. 2003).

Firing probably took place in a permanent structure such as a kiln, due to the slow rate of temperature increase that would have been required to drive chemically combined water from the thick-walled terracotta statues without catastrophic failure, as well as the sustained maximum temperature needed to harden them throughout. Neither of these could have been achieved by firing in an uncontrolled, 'open' bonfire firing (Shan et al. 2003), where the fuel and pottery load are in close proximity and the firing temperature is affected by changes in wind conditions and air temperature. 


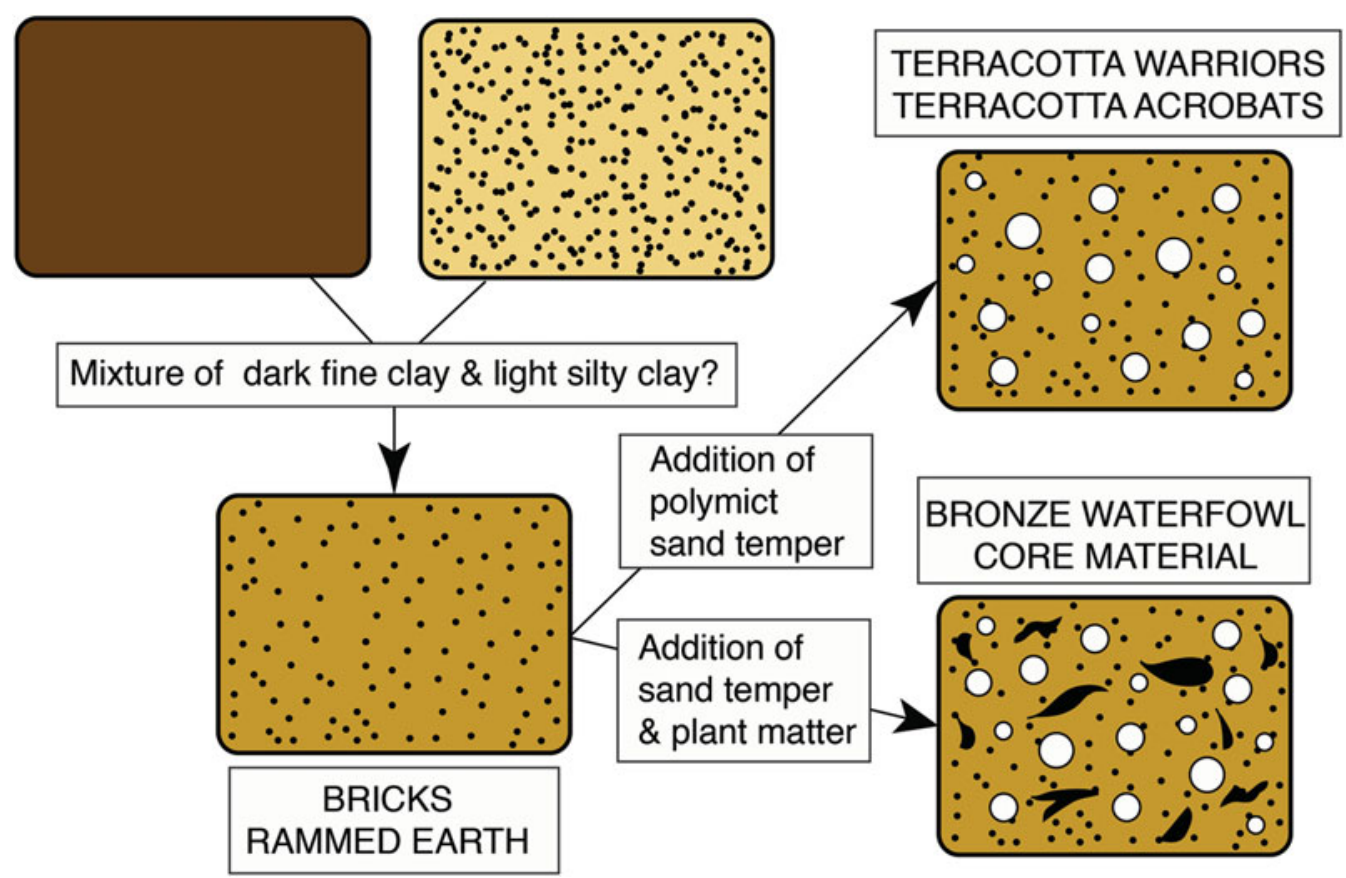

Figure 6. Schematic diagram of interpreted paste-preparation technology of ceramic artefacts from Emperor Qin Shihuang's mausoleum site.

\section{Organisation of production}

The compositional and technological links between the various types of artefacts analysed from Emperor Qin Shihuang's mausoleum complex (Figure 6) are suggestive of the way in which the production of ceramic objects for the necropolis was organised. These may indicate specifically that one or more large workshops manufactured several different types of ceramics. Such a scenario may also be suggested by the existence of similar stamps and inscriptions on both terracotta warriors and roof tiles excavated from the mausoleum (Ledderose 2000; Li et al. 2016), as well as the possible shared method of slab building between the warriors' legs and drainage pipes from the site (Nickel 2007).

The production of several quite different ceramic artefacts by the same workshop may provide tentative evidence to support the previously suggested existence of several 'cells' of multi-skilled craftsmen (e.g. Ledderose 2000; Martinón-Torres et al. 2014). These could be deployed on different tasks when needed and would be more adaptable than a single production-line arrangement (Martinón-Torres et al. 2014). The connection between the clay cores used to cast the bronze waterfowl statues and the production of other ceramics excavated from the mausoleum also suggests an unsuspected degree of 'cross-craft interaction' between potting and metalworking artisans.

An alternative explanation for the use of similar raw materials and paste-preparation technology in the manufacture of different ceramic objects is the existence of a centralised system of clay-paste processing and distribution at the production location (Figure 6).

(C) Antiquity Publications Ltd, 2017 
Under this interpretation, different workshops could have been responsible for specific ceramic objects but received their raw materials from a single source (Yuan \& Snethlage 2006). Such a system would make sense in terms of standardisation and quality control, given that clay was the essential ingredient of the approximately 7000 statues and a multitude of other ceramic items. As our analyses have shown, considerable care was taken to select and blend specific ingredients into the paste according to the type of artefact being produced. Strict adherence to these recipes would have been crucial in guaranteeing the successful production of such large numbers of complex artefacts. One way of ensuring this would have been to decouple raw material acquisition, processing (drying, crushing, refining) and paste preparation (clay mixing and tempering) from the processes of forming, firing and decorating the ceramics. Having a dedicated department responsible for the supply of clay to the various workshops would lead to less variability in composition than if this was left to individual production units. It would also help to ensure a constant supply of large quantities of raw material, which would have been a continual requirement (Ledderose 2001).

\section{Production location}

Our interpretation of the raw materials used in the manufacture of the terracotta warrior figures and other ceramic objects addresses the as yet unanswered question of their production location. The origin or 'provenance' of archaeological ceramics can be interpreted by locating the sources of their raw materials. An assumption in such studies is that clay and temper were obtained close to the site of pottery production (Quinn 2013: 119), which seems probable in this case. Previous scientific investigations have used a geochemical provenance approach to demonstrate that local clay deposits were indeed used (Gao et al. 2003; Shan et al. 2003; Lei et al. 2004). One such local candidate is the fine, silty loess that underlies much of central and northern Shaanxi Province. The similarity of this wind-blown material over large areas (Sun 2002), however, means that distinguishing between the loess of the Lintong area and that located farther afield near Xi'an, for example, will probably be difficult. Re-examination of the statistical classification of Gao et al. (2003: 68, fig. 3) and Shan et al. (2003: 303, fig. 4) indicates that there is, in fact, a rather poor correspondence between the local clay samples and the analysed terracotta statue fragments. This could be explained by the use of other, possibly more distant clay sources, or perhaps the modification of the local material via processes such as refining, clay mixing or tempering.

Detailed characterisation of the sand temper added to the terracotta warrior, the acrobat statues and the clay cores of the bronze waterfowl provides additional evidence for the location of their raw material sources, which was not considered in the previous provenance studies. Consideration of the Lintong and Xi' an bedrock geology indicates that the diverse mineral and rock types that occur within the temper material can be found on Mount Lishan to the south of the site (Figure 1b). This is composed of granite, gneiss, schist, amphibole, sandstone, siltstone and other lithologies, and is geologically distinct from the lowland area to the north and west. A complex arrangement of loess, river terraces from the nearby River Wei, and alluvial fans originating from Mount Lishan underlie the 
mausoleum complex (Figure 1b). It is possible to envisage juvenile, sub-angular to subrounded polymict sand of the type most probably used as temper being procured from these alluvial cones. Although no raw material sampling and analysis was undertaken in the present study, observations of outcrops of such material confirm their diverse clast composition.

Current evidence, therefore, suggests that the clay figures of the Terracotta Army were manufactured from locally available raw materials. Given that the long-distance transport of approximately 1050 metric tonnes of clay and temper seems unlikely, we can perhaps conclude that the production workshops were situated somewhere in the Lintong area. Moving the delicate 7000 or so $150-200 \mathrm{~kg}$ warriors, generals and horses would also have been a huge operation (Ledderose 2000); it is probable, therefore, that the production location was close to the mausoleum itself ( $\mathrm{Li}$ et al. 2016). Terracotta sculpture fragments and the remains of kilns were reported by local farmers approximately $200 \mathrm{~m}$ from pit 1 during the construction of the site museum (Yuan 1990; Ledderose 2001; Nickel 2007), but these were never investigated in detail. Subsequent surveys and building work inside and outside the known extent of the mausoleum complex have failed to detect further evidence of this type. One explanation may be that the ceramic workshops and kilns were dismantled after the completion of the mausoleum in $210 \mathrm{BC}$.

Stamps, inscriptions and painted symbols on certain terracotta warrior statues may indicate the activity of several different workshops, both in the Lintong area and perhaps $50 \mathrm{~km}$ away in the Qin capital of Xianyang (Yuan 1987, 1990; Li et al. 2016). Although our initial dataset does not support this idea, Gao et al. (2003: 68, fig. 3) may have detected such evidence. Their compositional classification reveals that the analysed terracotta statues of pits 1, 2 and 3 differ from one another in terms of their elemental composition. Although they did not explore the specific elements responsible for this pattern, and we therefore cannot rule out the possibility of differential preservation or post-burial contamination, the idea that specific workshops were responsible for the manufacture of statues for particular pits is an attractive one. The detailed microscopic analysis of additional samples from pits 2 and 3 , as well as stamped fragments, is a future research direction that will hopefully address this theory.

If we conclude that the majority of the terracotta warrior statues were produced at, or very close to, Emperor Qin Shihuang's mausoleum, then their links with other artefact types in our dataset may suggest the manufacturing location of these lesser-known ceramic objects. That the terracotta acrobats were produced close to their findspot is perhaps not surprising, given their similar size and manufacturing method to the statues of the Terracotta Army. Unfired bricks found in pit 2 suggest that these were also produced near the mausoleum (Li 2007b). The suggestion that the clay cores found within the ornate waterfowl sculptures were made on site, however, is novel, and has important implications for our knowledge of the production location of these and other ornate bespoke bronze artefacts, such as two large-scale, horse-drawn chariots found buried within the inner wall of the mausoleum (Figure 1a). It may be assumed, due to the delicate nature of the core material used to cast metal objects (particularly if they were not fired prior to use, as may be the case with the waterfowl sculptures), that they were produced at the same general location as the casing (Tan 1999).

(C) Antiquity Publications Ltd, 2017 


\section{Conclusions}

The detailed microscopic analysis of several fragments of the life-sized ceramic statues of Emperor Qin Shihuang's Terracotta Army and other clay-based objects recovered from his mausoleum has been used to reconstruct several aspects of the manufacturing technology of these impressive, numerically abundant artefacts. In particular, our analyses have indicated that instead of using unprocessed raw clay, as has been suggested previously, a surprisingly sophisticated process of raw material acquisition and treatment was employed to achieve a suitable paste for the manufacture of the figures. Clay appears to have been extracted from the extensive loess near the mausoleum site, and mixed with temper from mineralogically diverse alluvial sand eroded from Mount Lishan, a short distance to the south. This geological interpretation provides additional evidence that the 7000 statues were made somewhere within the mausoleum complex, most probably close to their site of deposition in three underground pits. Our analysis indicates that the bespoke ornate bronze sculptures unearthed from the site were also locally produced, for inclusion in the mausoleum.

Strong compositional and technological links exist between the terracotta statues and other clay-based artefacts from the First Emperor's necropolis, in terms of the use of a common base clay and other shared ingredients, which were treated in different ways according to the objects being produced. This may suggest that workshops were responsible for more than one type of ceramic product-a scenario suggested by the shared forming methods of the terracotta statues and certain architectural ceramics, and by similar inscriptions on these objects. Such an interpretation points to the existence of cross-craft interaction between potters and metalworkers at the mausoleum site.

An alternative explanation, and one that is favoured here, is that clay was procured and processed by a separate division of the 700000 strong workforce behind the building of the mausoleum, then handed out to the various ceramic workshops. This would ensure close adherence to a strict, standardised paste recipe, which surely represented a key factor in the smooth production of large numbers of statues, bricks and other objects. Centralising this part of the manufacturing operation would have enabled potting workshops to concentrate on the physical process of ceramic manufacture.

The attention seemingly given to the microscopic composition of the clay paste used to build the terracotta statues conforms to the tight control applied to other aspects of their manufacture, including the use of pre-fabricated moulds to produce a range of identical component parts, the assembly of these modules in a multitude of different combinations and the marking of the statues for administrative or quality-control purposes (Yuan 1987; Ledderose 2001; Li et al. 2016). A high level of standardisation also appears to have been applied to the production of other artefacts recovered from the site, such as the bundles of bronze arrowheads and crossbow triggers that were found in association with the Terracotta Army (Li et al. 2014; Martinón-Torres et al. 2014).

The construction of Qin Shihuang's enormous and highly complex mausoleum within the relatively short period between his ascension to the throne and his untimely death would surely have called for a high degree of organisation on many levels. The Qin Empire is thought to have surpassed other Chinese states in terms of mobilising masses of people and carefully coordinating their efforts towards ambitious goals (Yates 2007). The production 
of ceramics, metals and other artefacts deposited in the First Emperor's mausoleum clearly reflects a degree of organisation and efficiency that characterised many aspects of the empire and laid the foundations for imperial China.

\section{Acknowledgements}

The research presented here forms part of a collaborative project between the Institute of Archaeology, University College London (UCL) and Emperor Qin Shihuang's Mausoleum Site Museum. We are indebted to the late Peter Ucko and to Wu Yongqi, who first made this co-operation possible, and to Hou Ningbin for his ongoing support and encouragement. Since 2012, the project 'Imperial Logistics: the Making of the Terracotta Army' has been endorsed as a British Academy Research Project. Funding for the project was generously provided by the British Academy, the UCL Provost's Office, Rio Tinto and the Institute for ArchaeoMetallurgical Studies. Shao Anding of the Shaanxi Provincial Institute of Archaeology kindly provided access to the clay core samples. The PETROG digital stepping stage and point-counting software was provided by Conwy Valley Systems Ltd, Wales (www.petrog.com). Siran Liu translated some of the Chinese publications cited herein. All prepared scientific samples from this study are housed at the Department of Conservation, Emperor Qin Shihuang's Mausoleum Site Museum.

\section{References}

BARbieri-Low, A. 2007. Artisans in early imperial China. Seattle: University of Washington Press.

Freestone, I.C., N. Wood \& J. Rawson. 1989. Shang Dynasty casting moulds from north China, in P.E. McGovern, M.D. Notis \& D. Kingery (ed.) Cross-craft and cross-cultural interactions in ceramics (Ceramics and Civilization 4): 253-74. Westerville $(\mathrm{OH})$ : American Ceramic Society.

Gao, Z.Y., W.J. Zhao, G.X. Li, J.Z. Xie, G.H. Han, S.L. FenG, D.Y. FAN, Y. Zhang, Z.F. ChaI, R.W. Li, Z.L. Zhang \& J.X. Zhu. 2003. Neutron activation of sources of raw material of Emperor Qin Shi Huang's terracotta warriors and horses. Science in China 46: 62-70.

Hu, Y.Q., Z.L. Zhang, S. Bera, D. Ferguson, C.S. Li, W.B. Shao \& Y.F. Wang. 2007. What can pollen grains from the Terracotta Army tell us? Journal of Archaeological Science 34: 1153-57. https://doi.org/10.1016/j.jas.2006.10.026

Ledderose, L. 2000. The magic army of the First Emperor, in L. Ledderose (ed.) Ten thousand things. Module and mass production in Chinese art: 51-73. Princeton (NJ): Princeton University Press.

- 2001. The magic army of the First Emperor, in C. Blansdorf, E. Emmerling \& M. Petzet (ed.) The Terracotta Army of the first Chinese emperor Qin Shihuang. Monuments and sites II: 273-307. Munich: International Council on Monuments and Sites.

Lei, Y., B. Gao \& S. Yuan. 2004. Neutron activation analysis for the provenance study on Terracotta Army of Qin Shihuang. Nuclear Techniques 27: $38-27$.

(C) Antiquity Publications Ltd, 2017
LI, X. 2007a. An investigation into ceramic production for the First Emperor from the distribution of kilns in his tomb complex, in Research on Qin terracotta warriors and Qin culture, volume 14: 429-43. Xi'an: Shaanxi.

$-2007 \mathrm{~b}$. A pile of unfired bricks discovered in the north-west corner of pit 2 and related research questions, in Research on Qin terracotta warriors and Qin culture, volume 14: 422-28. Xi'an: Shaanxi.

Li, X., A. Bevan, M. Martinón-Torres, Th. Rehren, W. CaO, Y. Xia \& K. ZhaO. 2014. Crossbows and imperial craft organisation: the bronze triggers of China's Terracotta Army. Antiquity 88: 126-40. https://doi.org/10.1017/S0003598X00050262

Li, X., A. Bevan, M. Martinón-Torres, Y. Xia \& K. ZHAO. 2016. Marking practices and the making of the Qin Terracotta Army. Journal of Anthropological Archaeology 42: 169-83. https://doi.org/10.1016/j.jaa.2016.04.002

Liu, S., K. Wang, Q. CaI \& J. Chen. 2013. Microscopic study of Chinese bronze casting moulds from the Eastern Zhou period. Journal of Archaeological Science 40: 2402-14. https://doi.org/10.1016/j.jas.2012.11.010

Martinón-Torres, M., X. Li, A. Bevan, Y. Xia, K. Zhao \& Th. Rehren. 2014. Forty thousand arms for a single emperor: from chemical data to labor organization in the production of bronze arrows for the Terracotta Army. Journal of Archaeological Method and Theory 21: 534-62. https://doi.org/10.1007/s10816-012-9158-z

Nickel, L. 2007. The Terracotta Army, in J. Portal (ed.) The First Emperor: China's terracotta army: 159-79. Cambridge (MA): Harvard University Press. 


\section{Building the Terracotta Army}

Qin, G., X. PAN \& S. Li. 1989. Mössbauer firing study of terracotta warriors and horses of the Qin Dynasty (221 BC). Archaeometry 31: 3-12. https://doi.org/10.1111/j.14754754.1989.tb01051.x

QuinN, P.S. 2013. Ceramic petrography: the interpretation of archaeological pottery and related artefacts in thin section. Oxford: Archaeopress.

Rong, B. \& D. Lan. 2005. Polarized light microscopy on the fragments of Qin terracotta. Sciences of Conservation and Archaeology 17: 35-39.

Shan, J., J.Z. Zhou, C.S. Wang, P. Qin, Z.L. Zhang, J.X. Zhu \& Y.L Zhang. 2003. Preliminary study of provenance and firing style of terracotta from Qinshihuang Mausoleum. Nuclear Techniques 26: 299-305.

Shao, A., J. Mei, J. Yang, K. Chen \& W. Sun. 2015. Preliminary scientific analysis of bronze waterfowl clay core unearthed in the mausoleum of the First Emperor. Cultural Relics in Southern China 1: 72-80.

Stoltman, J.B., Z. Jing, J. TAng \& G. Rapp. 2009. Ceramic production in Shang societies of Anyang. Asian Perspectives 48: 182-203. https://doi.org/10.1353/asi.0.0013

Sun, J. 2002. Provenance of loess material and formation of loess deposits on the Chinese Loess Plateau. Earth and Planetary Science Letters 203: 845-59. https://doi.org/10.1016/S0012-821X(02)00921-4

TAN, D. 1999. A study of the techniques of bronze casting with clay moulds in Bronze Age China. Acta Archaeologica Sinica 2: 211-63.

WhitbREAD, I.K. 1986. The characterization of argillaceous inclusions in ceramic thin sections. Archaeometry 28: 79-88. https://doi.org/10.1111/ j.1475-4754.1986.tb00376.x
Wiedemann, H.G., A. Boller \& G. Bayer. 1988 Thermoanalytical investigation on terracotta warriors of the Qin Dynasty, in E. Sayre, P. Vandiver, J. Druzik \& C. Stevenson (ed.) Materials issues in art and archaeology. Symposium April 6-8, 1988, Reno, Nevada, USA (Materials Research Society Symposium Proceedings 123): 129-34. Warrendale (PA): Materials Research Society.

Wood, N. 2000. Plate tectonics and Chinese ceramics: new insights into the origins and distribution of China's ceramic raw materials, in M. Crick (ed.) Taoci no. 1, actes du colloque Le 'Blue et Blanc' du Proche-Orient à la Chine: 15-24. Paris: Revue Annuelle de la Société française d'étude de la céramique orientale.

YANG, H. \& G. YANG. 1979. Selections from records of the historian by Szuma Chien. Beijing: Foreign Languages.

YATES, R.D.S. 2007. The rise of Qin and the military conquest of the Warring States, in J. Portal (ed.) The First Emperor: China's terracotta army: 31-57. London: British Museum.

Yuan, Z. 1987. Qin pottery inscriptions. Xi'an: Sanqin.

- 1990. Research on the terracotta warriors and horses from the mausoleum of Emperor Qin Shihuang. Beijing: Cultural Relics.

Yuan, Z. \& R. Snethlage. 2006. Microscopic study of Chinese bronze casting moulds from the Eastern Zhou period, in Xi'an-Kaiserliche Macht in Jenesits: Grabfunde und Tempelschätze aus Chinas alter Hauptstadt: 165-80. Bonn: Kunst- und Austellungshalle de Bundesrepublik Deutschland.

Received: 24 August 2016; Accepted: 24 November 2016; Revised: 29 November 2016 